\title{
A divisa como conexão: representações da fronteira em documentário
}

\author{
Flavi Flavi Ferreira Lisbôa Filho \\ Débora Flores Dalla Pozza
}

Como é a fronteira Brasil-Argentina do ponto de vista de quem vive nela? $\mathrm{O}$ que os moradores de uma cidade da fronteira pensam sobre os moradores da cidade do outro lado? Quais as semelhanças e diferenças entre quem vive tão próximo, mas em países distintos? Esses são alguns questionamentos mobilizados pelo documentário Na Fronteira $(2015)^{1}$, que retrata a relação entre as cidades de Uruguaiana (Rio Grande do Sul, Brasil) e Paso de Los Libres (Corrientes, Argentina), separadas - ou seriam interligadas? - por uma antiga ponte, e cujos moradores cruzam de um país a outro frequentemente.

Realizado pela produtora independente Filmes de Abril e com direção de Maria Clara Escobar ${ }^{2}$, Na Fronteira ${ }^{3}$ foi veiculado pelo programa Sala de Notícias ${ }^{4}$ do canal Futura em 2015. Possui aproximadamente 12 minutos e conta com entrevistas de brasileiros e argentinos que vivenciam cotidianamente a situação de "ser da fronteira", "estar na fronteira" e o que isso implica.

Neste artigo nos propomos a identificar, a partir da análise documental da cultura baseada em Williams (2003), combinada aos pressupostos da análise textual (Casetti e Chio 1999), como o documentário em questão representa as identidades da fronteira 5 .

\footnotetext{
${ }^{1}$ É válido mencionar que há uma ampla variedade de documentários contemporâneos que contemplam a temática das fronteiras do Brasil. A título de reconhecimento, citamos: Terras (2009), de Maya Da-Rin; Do Outro Lado do Rio (2004), de Lucas Bambozzi; Doble Chapa (2014), de Leo Caobelli e Diego Vidart; A Linha Imaginária (2014), de Cíntia Langie e Rafael Andreazza; Fronteira da Grandeza (2017), de Dodge Billingsley e Cory Leonar; e Paralelo 10 (2012), de Silvio Da-Rin.
}

2 Maria Clara Escobar é cineasta e roteirista formada pela Escola de Cinema Darcy Ribeiro (RJ). Como diretora, realizou o documentário Os Dias com Ele (2013), sobre as memórias de seu pai, Carlos Henrique Escobar, intelectual preso e torturado durante o regime militar brasileiro - obra premiada como Melhor Filme na $16^{\circ}$ Mostra de Cinema de Tiradentes (SP). Também foi coroteirista e diretora assistente do filme Histórias Que Só Existem Quando Lembradas (2011), de Julia Murat, que estreou no Festival Internacional de Veneza e ganhou mais de 30 prêmios no Brasil e no exterior.

${ }^{3} \mathrm{O}$ documentário está disponível online pelo YouTube: $<w w w$.youtube.com/watch?v=rk0HyHZx3LQ $>$. Acesso em: 05 mai 2016.

${ }^{4}$ O Sala de Notícias existe desde a fundação do canal Futura, em 1997, e consiste em um espaço de circulação para reportagens documentais de até 13 minutos de duração. Desde 2011, o programa aposta na produção de realizadores independentes e o principal modelo adotado é via editais públicos para produtores audiovisuais de todo Brasil. Estas informações foram retiradas do site do programa: <www.futura.org.br/saladenoticias>. Acesso em: 08 jun 2016.

${ }^{5} \mathrm{O}$ presente trabalho se enquadra em pesquisa mais ampla de dissertação de Mestrado que não se detém sobre fronteiras propriamente, mas analisa produções documentais que mobilizam sentidos sobre identidades transnacionais na região que abrange o estado brasileiro do Rio Grande do Sul, parte central da Argentina e todo o Uruguai - espaço bastante equivalente ao bioma pampa. Nesse sentido, a categoria de fronteira é um operador conceitual problematizado em 
O trabalho se inscreve na perspectiva teórica dos Estudos Culturais e, por isso, considera o documentário enquanto manifestação material da cultura, ou seja, produto cultural formado em meio a um contexto complexo e específico. Não é nosso objetivo nos determos em teorias do documentário, uma vez que a obra audiovisual é apenas acionada como objeto de estudo e nos interessa focar nos sentidos que se engendram sobre a fronteira a partir da mesma. Cabe destacar que esse lugar de fala implica que enxerguemos a cultura como um modo inteiro de vida, que é, por excelência, dinâmico e da ordem do cotidiano/ordinário (Williams 2003). Bem além de espaço de reprodução ou desdobramento de aspectos sociais e econômicos, a cultura permeia toda a vida em sociedade, constituindo e reconfigurando as demais dimensões da mesma. Por isso que Hall (1997b) a toma como um repositório de valores e significados compartilhados na sociedade.

Mas para que os significados sejam produzidos e postos em intercâmbio, é preciso lançar mão da linguagem como meio para representar pensamentos, ideias e sentimentos através de sinais e símbolos - sons, palavras escritas, imagens, objetos, entre outros. Assim, a representação ${ }^{6}$ importa para a própria constituição das coisas e, portanto, a cultura é um processo primário tão relevante quanto a "base" econômica ou material da formação dos sujeitos sociais e dos eventos históricos (Hall 1997b).

Tais considerações, bastante iniciais, servem para esclarecer a trama de ideias fundamentais a partir da qual tecemos este artigo. $\mathrm{O}$ entendimento amplo e plural de cultura que adotamos, alinhado aos Estudos Culturais, perpassa todo o estudo, desde o processo de representação ligado ao gênero documentário, até a consideração das fronteiras como referências simbólicas, espaços próprios para a hibridação cultural, seguindo para a metodologia, com a opção pela análise documental da cultura enquanto ferramenta de pesquisa.

Representar possui dimensão simbólica, mas é um processo social carregado de materialidade. Pensamos isso aplicado à instância midiática. A linguagem, neste estudo, é tomada como o texto midiático, o documentário em análise. Para dar sequência, passamos a uma breve conceituação do documentário enquanto gênero audiovisual e entendemos como o processo de representação se relaciona ao mesmo.

momentos da pesquisa maior.

${ }^{6}$ Adotamos, neste trabalho, o termo representação, no singular, para nos referirmos ao processo em si, de utilização da linguagem para construir e fazer circular determinados sentidos na sociedade. Falamos em representações, no plural, ao tratar as materialidades em que o processo se manifesta, como no documentário em análise, por exemplo, por considerar a multiplicidade de possibilidades que ele pode assumir em um produto cultural. 


\section{Documentário e representação}

O documentário é uma narrativa construída por meio de imagens e sons que estabelece asserções ou proposições sobre o mundo. Ele se caracteriza pela intenção social do autor ao fazer a obra e é organizado espacial e temporalmente em torno da exposição do argumento (Ramos 2008). Algumas convenções ajudam a distinguir os documentários de outros gêneros audiovisuais: a predominância da lógica informativa, as entrevistas, a captação de som ambiente direto, a introdução de imagens que ilustrem situação mostrada em cena, assim como o uso de atores sociais ou pessoas em comportamentos e papéis cotidianos como se fossem personagens do filme (Nichols 2005).

Nichols (2005) elenca quatro ângulos para definir o que é documentário : primeiro, as instituições que produzem e promovem a circulação do filme, as quais realizam sua indexação/rotulação e estimulam uma suposição do público sobre o status de não-ficção e seu provável grau de objetividade, confiabilidade e credibilidade; segundo, os profissionais que fazem os documentários e possuem uma cultura profissional partilhada, com repertório comum de aspectos técnicos e de debates sobre questões sociais, além de particularidades que fazem com que cada documentário mude de acordo com as ideias do cineasta; terceiro, os textos (filmes e vídeos), estruturados de acordo com as lógicas de montagem da narrativa documental, de forma a operar muitas vezes com fórmulas já consagradas pela prática; e, por último, o público, que desenvolve um "desejo de saber" por meio da retórica persuasiva e da lógica informativa do documentário.

Para o autor, que considera todo filme como documentário, a diferença está entre os de satisfação de desejos, conhecidos como ficção, e os de representação social, de nãoficção. A última modalidade busca tornar visível e audível um recorte da realidade social que, alerta Nichols (2005), não é puramente reproduzida, mas representada - e pode transmitir visões de mundo e argumentos. Nesse sentido, destaca os aspectos técnicos que conferem falsa noção de autenticidade ou correspondência entre realidade e imagem no documentário:

"Certas tecnologias e estilos nos estimulam a acreditar numa correspondência estreita, senão exata, entre imagem e realidade, mas efeitos de lentes, foco, contraste, profundidade de campo, cor, meios de alta resolução (...) parecem garantir a autenticidade do que vemos. No entanto, tudo isso pode ser usado para dar impressão de autenticidade ao que, na verdade, foi fabricado ou construído. E, uma vez que as imagens tenham sido selecionadas e dispostas em padrões ou sequências, em cenas 
ou em filmes inteiros, a interpretação e o significado do que vemos vão depender de muitos outros fatores além da questão de a imagem ser uma representação fiel do que apareceu diante da câmera, se é que alguma coisa de fato apareceu" (Nichols 2005, 19-20, grifo do autor).

Por conta disso, Nichols (2005) relaciona a tradição do documentário com a impressão de autenticidade que o gênero transmite. A representação consiste em ideia fundamental para tal entendimento, pois é por meio dela que o documentário se engaja no mundo.

Segundo o autor, a representação opera de três formas. Uma é por meio do registro de pessoas, lugares e coisas reconhecíveis pelo público, o que promove a crença de que poderíamos ver aquilo por nós mesmos, que há fidelidade entre a imagem e as situações da realidade. Entretanto, ele pondera: as imagens não conseguem mostrar tudo o que efetivamente aconteceu e podem ser alteradas tanto durante como após o fato registrado. Além disso, inevitavelmente, o ato de filmar provoca alterações na realidade que se pretende representar, pois os atores sociais do documentário têm seu comportamento e personalidade afetados pela presença da câmera. A segunda maneira de representação elencada por Nichols (2005) é representar os interesses dos outros - público, sujeitos temas dos filmes, instituições que patrocinam as produções, entre outros. A última forma de representação busca a defesa de um determinado ponto de vista ou de uma perspectiva para interpretação dos fatos, de modo a conquistar consentimento e influenciar opiniões.

As ponderações que introduzimos sobre o conceito de representação vêm no sentido de evidenciar que o realismo da imagem é uma armadilha que não pode seduzir a análise de documentários, por mais que entendamos que o fascínio por contar histórias reais, por destacar temas cotidianos seja praticamente um consenso entre os documentaristas. Portanto, falar em termos de representação implica considerar escolhas simbólicas - técnicas e de conteúdo - que perpassam tanto a produção audiovisual como qualquer processo cultural.

O tema da representação ganha contornos mais universais no trabalho de Hall (1997b), para quem representar significa utilizar a linguagem, seus sinais e imagens para dizer algo significativo a alguém. Porém, o significado não está localizado no objeto, nem na pessoa, nem ainda na palavra, ele é construído no sistema de representação, por meio de códigos que estabelecem a relação entre o nosso sistema conceptual e o linguístico. Esses códigos são constituídos cultural e historicamente, por experiências e referências partilhadas dos sujeitos sociais. Para além da existência subjetiva, dentro de nossa mente, os códigos têm efeitos práticos e contribuem na organização e regulação das condutas 
sociais. Representar faz parte do processo de dar significado às coisas, o que engloba uma série de recursos: "[...] as palavras que usamos, as histórias que contamos acerca destas coisas, as imagens que produzimos, as emoções que associamos às mesmas, as maneiras como as classificamos e conceituamos, os valores que lhes damos" (Hall 1997b, 3).

Para estudar as imagens, as histórias, as palavras, as emoções, entre outros traços mobilizados nas representações da fronteira no documentário em análise, é preciso compreendermos brevemente o que se entende por fronteira e qual a possibilidade de falarmos em identidades a partir desse espaço.

\section{Fronteira: a um só tempo, distinção, articulação e pertencimento}

Quaisquer representações que se façam sobre fronteira em documentário põem em jogo sentidos sobre o tema compartilhados socialmente. Tanto os produtores audiovisuais que realizam um filme como o público que o assiste ativam uma complexa rede de referências noticiosas, cinematográficas, musicais, literárias, de discursos orais, entre outras fontes (Iglesias-Prieto 2010).

O senso comum aponta para a fronteira como espaço de demarcação de diferenças, limite geopolítico dos Estados-Nação e das normas, leis e soberanias dos mesmos. Em uma abordagem filosófica, Matthai (1991) amplia o entendimento para sustentar que as fronteiras políticas, linguísticas, econômicas e militares são desdobramentos artificiais de uma fronteira natural, de cunho psicológico, fruto da autoconsciência individual que distingue o "eu" do "outro". No entanto, o autor acrescenta que com as primeiras formações sociais, os humanos cultivaram um "eu" coletivo que os localizava no ambiente circundante e com os quais se identificavam, tendo os obstáculos físicos como limites, referências. Onde não havia tais marcos naturais, postulou-se a noção de fronteira política, estabelecendo - por convênio ou imposição - até onde se estendia a soberania e o poder de um Estado e onde começava a autoridade de outro. Tais demarcações tanto ofereceram aos grupos um sentido de segurança como estimularam uma ideia de transcendência para algo além; ambivalência imanente ao conceito de fronteira (Matthai 1991).

Fronteiras essas que Pesavento (2002) considera, antes de marcos físicos, como referências simbólicas que guiam classificações e percepções da realidade. Portanto, culturais, pois constroem sentidos sobre limites e hierarquias no imaginário social - ideia alinhada à já mencionada noção de fronteira psicológica, de Matthai (1991). Essa “abertura do conceito para além dos entraves físicos ou geográficos" é ativada também por 
Guerreiro $(2015,259)$ ao se voltar às narrativas fílmicas de transposição da fronteira México e EUA. Segundo ele, o termo sofre refrações diversas dentro e fora do cinema e pode-se falar em multifronteiras, as quais se manifestam, além de formas físicas, em ordens étnicas, linguísticas, afetivas e humanas.

Para além disso, apesar de muitas fronteiras serem originadas como resultado de conflitos bélicos, hoje diversas consistem em ponto geográfico de articulação, ambiente concreto de trocas comerciais e interações sociais, com pactualidades fluidas e ricos intercâmbios (Oliveira 2015).

São diversas as abordagens desenvolvidas para compreender tais espaços como categorias conceituais e analíticas: Iglesias-Prieto (2010) elenca vertentes desenvolvidas nos estudos fronteiriços e também desdobramentos das mesmas no cinema contemporâneo. As primeiras aproximações contextualizam a fronteira nos processos de globalização e integração, mas focam-se na especificidade de consistir em espaço físico de demarcação geopolítica entre Estados Nacionais e como isso condiciona os fenômenos que se desenrolam ali, tanto facilitando como constrangendo interações humanas. No cinema, essas linhas de abordagem costumam enfatizar mais os cenários e os entornos sociais do que os sujeitos que habitam a fronteira. O segundo conjunto de aproximações destaca o universo simbólico derivado da diversidade de culturas, grupos e pessoas nesse local: "as formas em que se redefine e reinventa esse espaço a partir das resistências que se expressam nas múltiplas experiências de vida, de representação social e de sentido que tudo isso gera" (Iglesias-Prieto 2010, 2, tradução nossa). As representações cinematográficas dessas aproximações detém-se nas relações sociais dos sujeitos que (re)conformam a fronteira, suas identidades, percepções, experiências e usos do espaço. O terceiro grupo de abordagens salienta não apenas os sujeitos, mas como a dimensão física da fronteira afeta as subjetividades, de modo que o desdobramento cinematográfico se dá em filmes que evidenciam a complexa psicologia e conflitos dos personagens, explorando a fronteira como condição de suas individualidades.

A construção histórica do conceito como um divisor de soberanias, de disputa de poder e de territórios também indicou para uma conotação junto ao imaginário social, por longo tempo, da fronteira enquanto lugar propício para contravenções - contrabando, rota de fuga para quem infringe a lei, entre outras (Nogueira 2007). Iglesias-Prieto (2010), ao se deter nas abordagens cinematográficas da fronteira México-EUA, avalia que existe uma sobre-representação midiática e hiper-construção imaginada desta fronteira que muitas vezes consolida estereótipos. O cinema mainstream norte-americano, por exemplo, reproduz o postulado de que as fronteiras são centros de perdição e vício (IGLESIASPRIETO 2010). Já a análise das jornadas cinematográficas de transposição desta mesma 
fronteira, empreendida por Guerreiro (2015), demonstra como a ideia de periferia marca a fronteira nas narrativas, como se a transposição simbolizasse a fuga das zonas periféricas para locais centrais, onde há mais recursos e oportunidades. Entretanto, ao alcançar tais centros, os personagens se confrontam com um novo lugar de margem ao qual são subjugados, o que redimensiona a noção de periferia nas narrativas - demonstrando que as fronteiras podem ser de ordens diversas à física, também com caráter social, cultural, linguístico e até afetivo.

A conotação negativa sobre o tema também pode ser percebida pela cobertura jornalística no Brasil dos acontecimentos fronteiriços. Em uma análise do agenciamento que a mídia local e a nacional realizaram sobre as fronteiras internacionais brasileiras entre 2005-2006, Silveira (2012) aponta para a manutenção de um enquadramento discursivo que privilegia situações de violência, as quais frisam a ausência do Estado, os riscos à segurança pública, ao patrimônio e à ordem tributária. A autora interpreta a cobertura como "alarmes de incêndio" que alertam continuamente a comunidade local e nacional para seus perigos. Assim, "a singularidade de uma sociedade engendrada pelo encontro multicultural é subsumida pelo rótulo genérico de fronteira problemática" (Silveira 2012, $82)$.

É por isso que, novamente de acordo com Pesavento (2002), percebemos que ser fronteira implica ser borda, margem, estar fora do centro. Tal condição acarreta em um valor universal da fronteira - também já enunciado por Matthai (1991) - a transcendência: "envolve o distanciamento e o estranhamento como atitude, e a ambivalência e a ambiguidade como condição de ser" (Pesavento 2002, 38).

Essa ambivalência, vinculada ao fato de se tratar também de um espaço de trânsito, passagem, favorece ainda a possibilidade de contato, de mistura e a geração de algo novo, diferente. É plausível relacionarmos esse entendimento com as ideias de Canclini (2003), que considera as fronteiras, assim como as grandes cidades, enquanto territórios propícios para a hibridação cultural: processos em que as estruturas ou práticas que existiam de formas separadas se combinam e geram novas estruturas, objetos e práticas, mesclados, integrados e, se poderia dizer, mais plurais. As mesclas interculturais, segundo o autor, surgem tanto da criatividade individual como da coletiva a partir da reconversão, a adaptação de técnicas e saberes de acordo com demandas econômicas, sociais e culturais.

Provavelmente bastante conectado à hibridação, o processo de integração regional ganha força em tempos de fronteiras com novos ritmos tanto de volume quanto de importância: 
“Os números mostram que, de maneira geral, as fronteiras têm consolidado um aumento no seu volume populacional e nas atividades econômicas em todos os países da América do Sul e do Caribe. Em praticamente todos os países a taxa de crescimento da população nas fronteiras alcançou mais que o dobro do restante da nação. Isto é causa e é efeito da forte função das fronteiras no processo de integração regional. Há um amadurecimento congênito desses territórios como vetores deste processo integracionista, fato que tem contribuído para a ampliação de sua visibilidade" (Oliveira 2015, 10).

Mas, apesar do crescente movimento integracionista, cada fronteira é diferente das outras e passa por permanente reconstituição. Iglesias-Prieto (2010) faz a ressalva de que uma fronteira geopolítica nem sempre resulta em uma maior interação material e simbólica, pois esta depende do nível de "transfronteridade" do sujeito que vive e experimenta a condição de fronteira. Trata-se da quantidade, frequência, intensidade e direção dos intercâmbios e das relações entre os lados, bem como o sentido social e cultural desse cruzamento. O nível de interação afeta e marca as subjetividades: "um maior nível de transfronteridade supõe maior nível de interação, cruzamento e compromisso com 'o outro lado', o que por sua vez supõe maiores capacidades e riqueza cultural, assim como maior complexidade identitária e de representação" (Iglesias-Prieto 2010, 3, tradução nossa).

Para enfatizar a relação entre sujeito e lugar, atentando para o olhar dos habitantes sobre a fronteira e sobre os relacionamentos com seus vizinhos e com os compatriotas do centro, Nogueira (2007) apresenta o conceito de fronteira vivida. Assim, propõe pensar tal local como espaço de referência identitária, identidades territoriais que se manifestam na própria experiência de habitar o lugar.

Com Woodward (2014), lembramos que o processo de identificação pressupõe uma vinculação necessariamente consciente a determinados traços/aspectos culturais e é baseado em oposições simbólicas, ou seja, a identidade é marcada pela diferença - via de regra, reconhecemos o que somos em contraponto àquilo que não somos.

$\mathrm{Na}$ linha dessa proposição, são duas as maneiras pelas quais a fronteira se estabelece como espaço de identidade, segundo Nogueira (2007): uma essencialmente nacional, em contraponto às regiões centrais, porque ser "da fronteira" é diferente de ser do centro, justamente pela convivência com o outro, com a diferença nacional e com os elementos culturais ou simbólicos de outra nação; outra forma é pela interação de identidade binacional, em que os dois lados se reconhecem como fronteiriços, superando 
os limites formais do Estado-Nação. Assim, é possível conceber também uma noção de identidade que transpõe divisas: “[...] a fronteira política impõe, por necessidade do Estado, uma disjunção histórica, um corte que institui uma diferença, que dificulta uma identidade fronteiriça, e que a sociedade fronteiriça procura romper" (Nogueira 2007, 32).

Essa identidade fronteiriça binacional se assemelha ao que Iglesias-Prieto (2010) reconhece como transfronteiriço, relativo a uma dimensão local ou regional desse espaço, mas que presume intercâmbio internacional, com circulação de pessoas, bens materiais e elementos culturais entre um e outro país, o que gera uma intensa e cotidiana carga simbólica.

É possível entender com mais nitidez as identificações transfronteiriças se considerarmos, com França $(2002,66)$, que os processos de nação e de internacionalização não são elementos opostos que podem eventualmente mesclar-se, mas "implicam reversões e superposições de um a outro". Assim, viabiliza-se falar em narrativas de pertencimento - alimentadas simbólica e socialmente - a reidentificações imaginárias que estão para além dos limites do Estado-Nação. Essas narrativas de pertencimento espaciais podem ser representadas de distintas maneiras nos filmes, conforme a autora: uma delas é estabelecendo territórios de pureza, essencialização de identidades; a segunda é retratando a situação do mundo atual como um quadro de transnacionalização ao qual estamos fatalmente subordinados; e a terceira é propor uma comunidade à força da diferença, composta de vizinhanças mutáveis, mas que "promovem um diálogo confraternizante e uma experiência de compartilhamento" (França 2002, 67). A pesquisadora ainda recorda que as identidades não são entidades fechadas, destituídas de recortes e nuances em suas constituições.

Antes de partirmos à apresentação do percurso metodológico, também salientamos a advertência de Hall (1997a, 8, grifo nosso) de que as identidades não emergem simplesmente de uma dimensão subjetiva, de um centro interior, mas do “diálogo entre os conceitos e definições que são representados para nós pelos discursos de uma cultura e pelo nosso desejo (consciente ou inconsciente) de responder aos apelos feitos por estes significados". Ou seja, as identidades se constituem através da cultura, no interior dos sistemas de representação.

\section{As representações no documentário: a análise documental da cultura como proposta metodológica}

Representar é um processo material, mas o significado gerado a partir dele depende de 
uma dimensão simbólica. Como já mencionamos na abertura deste estudo, tal dimensão é associada à cultura, grande repositório de significados e valores compartilhados em sociedade (Hall 1997b). Os meios de comunicação não são apenas reprodutores de cultura, mas constituintes dela, e o documentário, por sua vez, é um produto desenvolvido por práticas sociais que se insere nessa lógica.

Segundo Williams (2003), três instâncias devem ser consideradas para uma análise apropriada da cultura: a ideal, a documental e a social. A ideal remete a valores universais de uma linha geral de desenvolvimento da humanidade. A social se refere à descrição de um modo particular de vida, que expressa significados inclusive nas instituições e no comportamento ordinário. Já a documental diz respeito às obras intelectuais que registram o pensamento e a experiência do ser humano. Para o autor, a análise documental da cultura é uma atividade de crítica em que se descreve e avalia as manifestações de acordo com os detalhes de linguagem, forma e convenção, assim como a natureza do pensamento e da experiência.

É possível entender o documentário como um documento, um registro da cultura vivida, e assim, realizar uma análise cultural focada na categoria documental. Ainda mais ao observar as propostas de Nichols (2005) quanto ao documentário como materialidade de representação dos eventos com pretensa autenticidade a partir de instrumentos de gravação. Contudo, vale registrar que Williams (2003) alerta para a necessidade de incluir todas as três perspectivas para uma análise apropriada da cultura. Assim, a análise documental deve consistir em ponto de partida para pensar o modo específico de vida, a dimensão social relacionada, bem como os valores implícitos e explícitos aos quais o registro remete, na esfera ideal. A ideia é refletir sobre o produto cultural considerando o contexto específico em sua complexidade.

Por limitação de tempo e espaço no presente trabalho, vamos privilegiar a análise documental, considerando a materialidade do documentário e as construções simbólicas efetivadas no mesmo, e buscar relacioná-la à revisão teórica a respeito da fronteira enquanto espaço de referência identitária. O esforço é de recuperar os elementos concretos do texto audiovisual, com arranjo organizado por conta das convenções do gênero documentário e de forma a construir determinados sentidos.

Para tanto, nos inspiramos nos preceitos da análise textual (Casetti e Chio 1999). Trata-se de um procedimento que reconstitui a estrutura e os processos do objeto em termos qualitativos. Considera os produtos audiovisuais como construções a partir do material simbólico dotadas de consistência e autonomia, que obedecem a regras de composição específicas e produzem certos efeitos de sentido.

A análise textual desloca a atenção aos elementos concretos do texto e aos modos 
como ele se constrói, além de estender a interpretação para o significado em seu sentido global, valorizando os temas de que se fala e as formas de enunciação. Ela pode simular uma entrevista do analista ao texto, alinhando núcleos-guia sugeridos por Casetti e Chio (1999): história; sujeitos e interações; o que é posto em cena; e textos verbais.

A história trata dos eixos narrativos - se é apenas um que estrutura a história ou se são vários e, nesse caso, quais as interações entre eles; os sujeitos dizem respeito aos personagens do audiovisual, qual sua densidade no tempo e no espaço e sua função no desenvolvimento da história; o que é posto em cena se refere aos espaços evidenciados, sua ambientação e modos que aparecem, considerando enquadramentos, movimentos de câmera e montagem, entre outros aspectos técnicos, além da relação das imagens com os textos verbais; esses últimos, por sinal, consistem nos conteúdos das falas, estilos de linguagem, valorações explícitas ou implícitas que mobilizam. Vamos, na sequência, partir desse esquema de leitura para operacionalizar a análise documental.

\section{Na Fronteira: documento cultural em análise}

“Uruguaiana, RS, Brasil, 136.364 habitantes. Paso de Los Libres, Corrientes, Argentina, 43.251 habitantes. Duas cidades vizinhas, divididas e conectadas por uma ponte, o Rio Uruguai e duas alfândegas" - a frase que abre o documentário Na Fronteira o introduz aqui em nossa análise e também já indica uma das características da narrativa: sem apresentadores ou entrevistadores que apareçam em tela, é conduzida por frases escritas com essa, que surgem sem regularidade, e por depoimentos de brasileiros e argentinos que habitam as cidades retratadas.

Como já mencionado, esta obra audiovisual tem pouco mais de 12 minutos. Boa parte desse tempo se dedica aos depoimentos. Reconhecemos três eixos, dentro das entrevistas, que organizam a história em sequência temporal: o primeiro se refere à Escola Paso de Los Libres e seus integrantes, instituição localizada em Uruguaiana, mas com o nome da cidade argentina vizinha, inclusive com a grafia em espanhol; o segundo também contempla um colégio, mas sediado no outro lado da fronteira (Escuela Verón); o último, com maior duração, destaca relatos de vida de pessoas que vivem na fronteira e mostra como tais trajetórias são moldadas por essa situação e de que forma os indivíduos se relacionam a ela.

Os eixos consistem em base para descrevermos os sujeitos que participam desta obra audiovisual. Da Escola Paso de Los Libres, são o regente da banda escolar, uma professora e um aluno que aparenta aproximadamente 10 anos. Todos se comunicam em 
português. Já da Escuela Verón, participam três professoras, sendo que uma delas é diretora da instituição e outra aparece em imagens em plano aberto da entrevista, porém não fala na edição final; há também duas meninas que figuram em uma cena interpretando as presidentes do Brasil e da Argentina na época do documentário (2015), Dilma Rousseff e Cristina Kirchner, respectivamente. Nesse trecho, o idioma falado é espanhol e a obra audiovisual dispõe de tradução em português durante as falas. O terceiro momento, de ênfase nas histórias de vida, destaca um caminhoneiro que viaja de um país ao outro e trabalha como taxista em Uruguaiana nos momentos em que não tem carga ou ela está retida na aduana, uma dona de pensão fronteiriça que fala português com forte sotaque espanhol e uma argentina presidente de uma escola de samba, que mora em Paso de Los Libres e leva as filhas para estudar diariamente em Uruguaiana.

A obra audiovisual dá voz a pessoas comuns que expõem suas perspectivas de vivenciar e interpretar a moradia em zona fronteiriça, o que nos remete que uma das maneiras de representação (Nichols, 2005) no documentário é mostrar o interesse dos outros, como os sujeitos relacionados à temática. Mesmo que não seja um interesse deliberado dos indivíduos participar do filme, o simples fato de contemplá-los na produção já denota uma valorização de seus pontos de vista e, se eles aceitaram contribuir no processo, foi porque julgaram válida a realização de um material sobre a temática da qual falaram a respeito.

Quanto ao que é posto em cena - imagens, enquadramentos, trilha sonora notamos que não há alta qualidade de imagens. Muitas vezes a câmera parece estar na mão da documentarista e não estabilizada, o que remete a um formato "amador". Presumimos que isso também enfatiza o conteúdo, sinalizando que aquilo que aparece em tela está ao alcance de quem quiser ver presencialmente, já que uma gravação tão simples foi capaz de registrar. Também se faz uso do áudio ambiente nas imagens de transição, entre os depoimentos. Nesse sentido, resgatamos as ideias de Nichols (2005) sobre a impressão de autenticidade vinculada ao gênero documentário e sobre o primeiro modo de representação elencado pelo autor, que é do registro de pessoas, lugares e coisas reconhecíveis pelo público, buscando demonstrar fidelidade entre imagem e situações da realidade.

Como grande parte do documentário é conduzido pelos depoimentos, a maioria das imagens é de registro deles. Em sua maioria, são de plano médio, aparecendo do busto até a cintura do entrevistado e permitindo observar parte da composição de fundo, contextualizando a fala dos sujeitos. A única exceção desse formato é das professoras da Escuela Verón, que aparecem juntas em uma imagem em plano aberto, mas duas delas também foram retratadas em plano médio durante suas falas. 

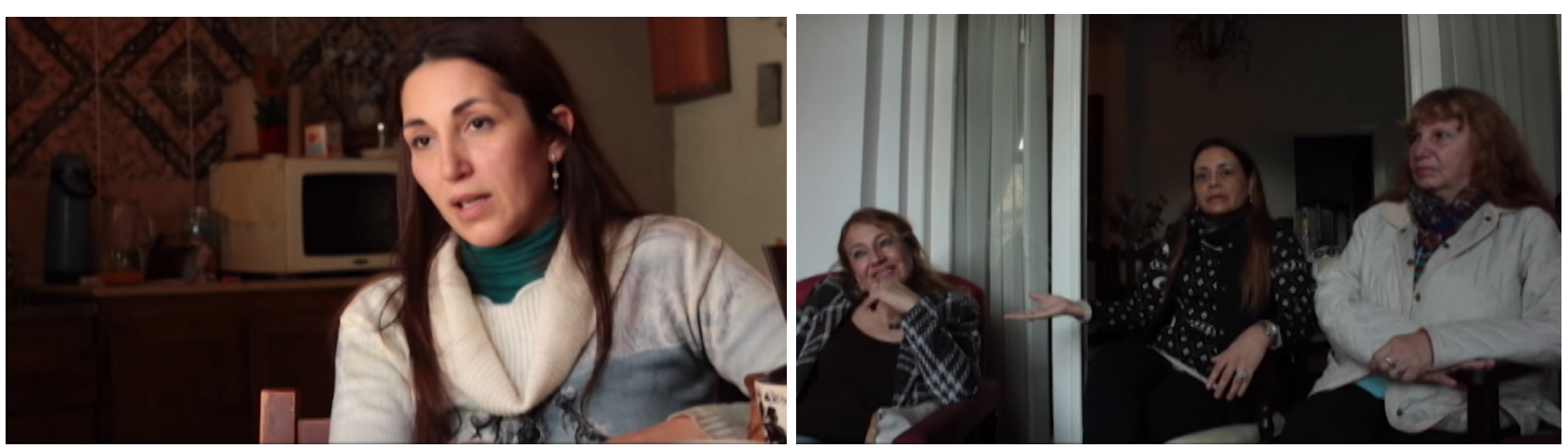

Figuras 1 e 2: imagem de entrevista em plano médio, com dona de pensão fronteiriça, e de plano aberto com três professoras da Escuela Verón, respectivamente. (Fonte: documentário Na Fronteira)

As imagens de transição são bastante variadas. Muitas delas fazem referência aos conteúdos dos depoimentos. Nesse ponto, percebemos que as imagens são mais diversificadas quanto a enquadramentos e movimentos de câmera do que no restante do documentário. Outras cenas de transição parecem falar por si ou complementar ideias introduzidas pelas frases escritas, como uma composição que mostra a ponte que liga as duas cidades ao fundo. Também nessa linha uma imagem de duas torres com bandeiras do Brasil e da Argentina hasteadas lado a lado; outra em que aparece um rádio de carro sintonizado em frequência na qual o locutor fala em português e, quando uma mão troca a frequência, para em estação com locução em espanhol; cena de rua com vários carros e placa escrito "migração"; outra placa indica "Bem-vindo a Uruguaiana - aqui começa o Brasil".

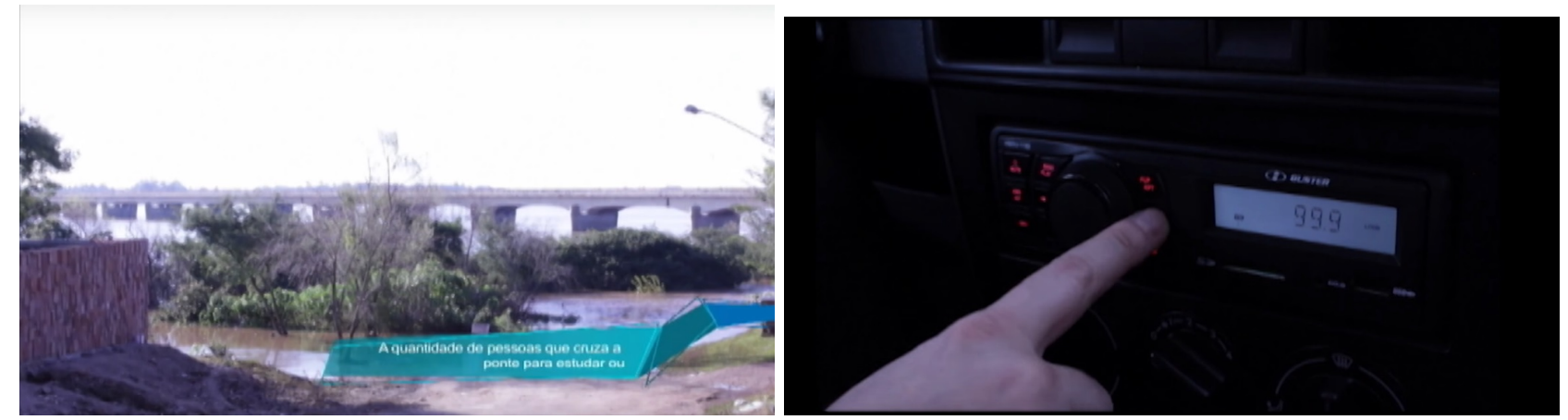

Figuras 3 e 4: cena com Rio Uruguai e ponte ao fundo (aparece frase escrita em tela) e imagem de rádio com mão prestes a trocar a frequência. (Fonte: documentário Na Fronteira)

Já que falamos das frases escritas que surgem em tela, passamos daquilo que é posto em cena no documentário para o texto verbal propriamente dito. Começando pelas frases, notamos que, além de transmitir dados, elas também carregam interpretações sobre a fronteira representada. A seguir, trazemos alguns trechos dos escritos que aparecem ao 
longo da narrativa e demonstram isso: "Diariamente cruzam essa fronteira cerca de 4.000 pessoas [...]. Uma ponte, de dois quilômetros, que divide e ao mesmo tempo aproxima pessoas, países, línguas e culturas”; “[...] A quantidade de pessoas que cruza a ponte para estudar ou por motivos familiares diariamente é intensa. Por isso, os modelos de relações e educação são sempre repensados"; “Vistas como lugar de passagem, as pessoas que ficam são as que conhecem a história de ambas cidades. São elas que, de forma informal, redefinem as fronteiras".

Tais frases concebem a fronteira como espaço de aproximação entre os habitantes dos distintos países, para além de divisa. Frisa-se assim, o cotidiano, a vivência, as relações de troca e cooperação. Além disso, ao considerar as fronteiras dinâmicas, vivas, com possibilidade de se redefinir pelas pessoas que vivem ali, o documentário se alinha à noção de fronteiras culturais, como referências simbólicas sujeitas a alterações junto às transformações culturais do tempo e espaço em que se inscrevem. Esses pontos de vista nos remetem ao terceiro modo de representação apresentado por Nichols (2005), em que o documentário oferece uma perspectiva para interpretação das situações e conquista consentimento de quem o assiste. Além disso, reconhecemos que a obra audiovisual se alinha à segunda linha de abordagens da fronteira elencadas por Iglesias-Prieto (2010), uma vez que as representações destacam as relações sociais dos sujeitos que configuram e reconfiguram tal espaço, expondo suas percepções, experiências de vida e identificações a partir de todo esse universo simbólico derivado da diversidade cultural.

Quanto aos conteúdos dos depoimentos, muitos frisam a mistura entre as nacionalidades no espaço fronteiriço. Uma professora da Escola Paso de Los Libres comenta sobre os alunos que têm pai argentino e mãe brasileira ou vice-versa e que a cultura de Uruguaiana é matizada pela argentina em função da comunicação direta. A diretora da Escuela Verón lembra relatos de pessoas mais velhas de que sempre foi natural cruzar a ponte, ir à Uruguaiana em alguma urgência ou até mesmo encontrar matrimônios entre pessoas de diferentes nacionalidades. Uma professora da Escuela complementa: “a ponte não nos separa, nos une" - ou seja, há uma ênfase desse espaço de fronteira como propício a integração, aproximação. Nesse ponto, fica evidente que o documentário efetiva um recorte da realidade retratada e que as representações contemplam determinados sentidos em detrimento de outros. Por exemplo, as contravenções e riscos à segurança e ao patrimônio nacional, tão acentuados no enquadramento jornalístico (Silveira 2012) não são sequer mencionados nesta obra audiovisual em análise. A falta de alusão à criminalidade, legalidade ou ordem social podem ser interpretadas tanto como inocência da realizadora do documentário, que propõe representações positivas sobre o cotidiano fronteiriço, assim como superação dos "valores de estigmatização impostos à cobertura das fronteiras" 
(Silveira 2012, 85) e dos estereótipos bastante consolidas no cinema mainstream norteamericano sobre tais espaços (IGLESIAS-PRIETO 2010), uma vez que faltam produções midiáticas a respeito do cotidiano fronteiriço que constituam instrumento de construção ou afirmação das identidades dos grupos sociais desses locais.

Seguindo nesse sentido, a mescla entre culturas e nacionalidades é bastante evidenciada ao longo da narrativa, indo ao encontro da proposta de Canclini (2003) de que as fronteiras são espaços propícios para o processo de hibridação cultural. Isso não quer dizer que as diferenças sejam esquecidas, mas parecem representadas em uma perspectiva tolerante que valoriza o enriquecimento com o contato entre as nações. A interação material e simbólica, bastante enfatizada, nos remete a um alto nível de "transfronteridade" (Iglesias-Prieto, 2010), com uma dinâmica intensa de cruzamentos entre os lados da fronteira conectados pela ponte.

A proximidade é um incentivo para iniciativas que promovam trocas de conhecimento. A banda escolar, segundo o regente, se apresenta frequentemente na Argentina, o que para as crianças já significa conhecer mais do outro país, mesmo que seja só atravessar a ponte, e também provoca interesse nas crianças argentinas, já que lá não existe o costume de bandas nas escolas. O Projeto Escola Intercultural Bilíngue de Fronteira, assinado por uma ação bilateral Brasil-Argentina para se ensinar português e espanhol como segunda língua nas escolas fronteiriças, foi destaque na fala de professora da Escuela Verón.

A temática da integração entre Brasil e Argentina ganha seu ápice na cena em que duas meninas da Escuela Verón interpretam Dilma Rousseff e Cristina Kirchner, presidentes dos países na época do documentário, em um teatro escolar: a "pequena Cristina", após conhecer o Brasil, fala "estamos tão perto, nos conhecemos tão pouco, mas temos um ideal em comum - um lugar onde reine a paz, a amizade e a igualdade". Para encerrar, diz "vamos Brasil" e a "pequena Dilma" responde "Vamos Argentina”. Em um registro de um momento tão simples, materializam-se sentidos sobre relações diplomáticas, integração regional e igualdade entre nações e indivíduos. Ficam questionamentos se a integração entre os países e suas relações diplomáticas podem ser resumidas a uma representação tão positiva e amistosa. Candea (2005), em um estudo dos avanços e resumos na relação Brasil-Argentina, demonstra a existência de uma instabilidade no século XIX, que progrediu rumo à estabilidade estrutural pela integração nos séculos XX e XXI. De acordo com o autor, “as fases intermediárias foram instabilidade conjuntural e busca de cooperação (1898-1961), instabilidade conjuntural com rivalidade (1962-1979) e construção da estabilidade estrutural pela cooperação (1979-1987) e pela integração (desde 1988)" (Candea 2005, 179). Assim, nos últimos anos, especialmente no 
século XXI, é possível reconhecer que existe de fato um cenário de estabilidade nas relações, representado pela integração e cooperação entre os "países-irmãos".

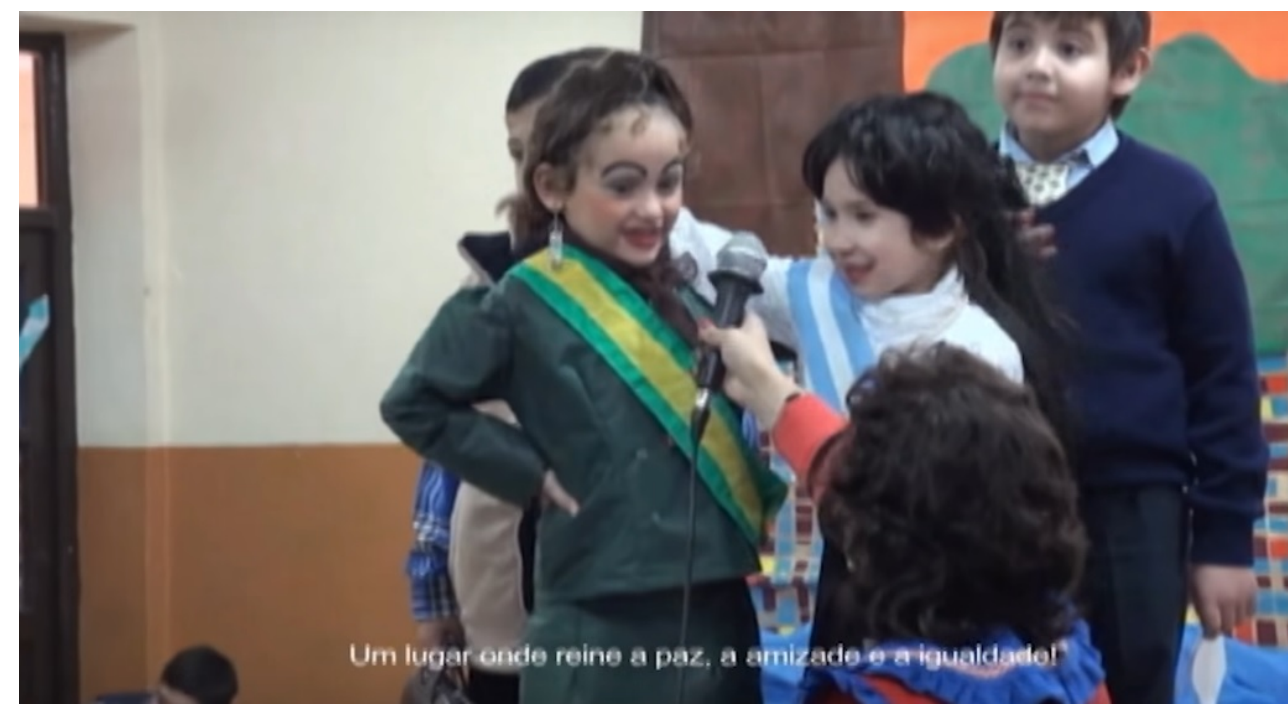

Figura 5: Documentário registra teatro escolar em que meninas argentinas interpretam Dilma Rousseff e Cristina Kirchner. (Fonte: documentário Na Fronteira)

A rotina da fronteira parece ganhar mais ênfase nas falas dos sujeitos que relatam suas histórias de vida - o caminhoneiro e taxista, a dona de pensão e a presidente da escola de samba. O primeiro conta sobre o processo de passar na migração e de viajar a Buenos Aires; a dona de pensão diz que em feriados o local lota-se de brasileiros que querem fazer compras e no verão a aduana "explode" com os argentinos que vão às praias brasileiras, independente da crise em que seu país esteja ou da cotação da moeda; o último depoimento do documentário é da presidente da escola de samba, que relata uma situação especial por conta da configuração familiar, a qual exige que vá quatro ou cinco vezes por dia à Uruguaiana para buscar as filhas na escola, e se considera muito próxima e amiga dos brasileiros - "para mim não é outro país, é a escola que fica longe [...], então, para mim não é uma fronteira". Esse é o último texto verbal do documentário.

A interpretação mais latente que tivemos a partir da análise documental foi sobre como as identidades de fronteira são representadas. Lembramos que Nogueira (2007) indica que a fronteira pode ser espaço de identidade de duas formas - uma nacional, em que o "ser da fronteira" se estabelece em contraponto ao ser de regiões centrais, e outra é a identidade fronteiriça binacional, que transpassa limites geopolíticos. O audiovisual em análise mobiliza sentidos reiteradamente sobre a identidade binacional, partilhada entre moradores dos dois países, como pudemos ver no destaque à conexão entre as cidades por meio da ponte, à integração, à mistura entre as nacionalidades nas relações familiares e aos 
projetos de troca de conhecimento, por exemplo. Essa identidade binacional é da ordem do transfronteiriço (Iglesias-Prieto 2010), pois mantém sua dimensão local ao tempo que presume intercâmbio internacional, o qual se desdobra em uma cotidiana carga simbólica nas vidas dos sujeitos e em suas relações. Com isso, ainda conectamos o documentário $\mathrm{Na}$ Fronteira à terceira forma de fundar narrativas de pertencimento em filmes enunciada por França (2002): propondo uma comunidade que vivencia compartilhamentos e dialoga de maneira fraterna, embora marcada pelas diferenças que coadunam no interior de suas identificações.

Alguns apontamentos feitos por Oliveira (2015, 12-13) sobre cidades que se mesclam territorialmente na fronteira e o caráter dinâmico e dialético de suas relações nos parecem muito próximos a tal interpretação obtida na análise:

“Nessas regiões entre nações, praticamente não se passam réguas estabelecendo-se limitações específicas. As linhas que ali se assentam não são fixas, são trementes, movem-se, abarcando um 'todo único', ainda que pouco harmonioso, que se cobre com tecidos de relações sistêmicas."

Assim, as representações efetivadas vêm muito no sentido de fortalecer o pertencimento a uma identidade possível fronteiriça, diferente ao mostrado nos estereótipos do cinema mainstream e na cobertura jornalística hegemônica sobre os acontecimentos fronteiriços, o que configura o documentário em análise como uma alternativa ao enquadramento discursivo tão reiterado e disseminado socialmente - das fronteiras "problemáticas", relacionadas aos riscos, aos perigos, às contravenções.

\section{Considerações finais}

O estudo que apresentamos mobilizou conceitos como cultura, representação, documentário, identidade e fronteira para buscar entender como o documentário enquanto produto cultural representa identidades específicas. No caso, a fronteira foi tomada como espaço de referência identitária para as representações materializadas na obra audiovisual Na Fronteira.

Identificamos que o documentário em questão utilizou os três modos de representação elencados por Nichols (2005) para construir sua narrativa: primeiro, com o registro de situações próprias do contexto de fronteira de maneira que o público possa presumir a correspondência fiel entre imagem e realidade retratada; depois, representando 
interesses dos sujeitos que vivem nos espaços fronteiriços ao dar voz a pessoas comuns, suas vivências e percepções sobre o local; e por último indicando uma perspectiva de interpretação dos fatos por meio de frases escritas que aparecem em tela e fornecem, além de informações, pontos de vista que direcionam o olhar da audiência sobre o recorte social.

Além disso, este trabalho consiste num esforço preliminar de pesquisa para aplicar a análise da cultura (documental) como procedimento metodológico no estudo das representações de identidades em documentário. Mesmo se tratando de um protocolo bastante amplo e complexo, foi possível realizar um cotejamento entre a materialidade do texto audiovisual e os conceitos trazidos a respeito da fronteira enquanto espaço de referência identitária.

Com o percurso, conseguimos reconhecer que o documentário em análise clama principalmente por representações de uma identidade binacional de fronteira (Nogueira 2007), compartilhada por habitantes brasileiros e argentinos das duas cidades retratadas, como se formassem uma comunidade de reidentificações imaginárias de ordem transnacional, apesar das diferenças que a marcam (França 2002). Tais ideias remetem à "transfronteridade" (Iglesias-Prieto 2010), ao hibridismo cultural (Canclini 2003) no espaço fronteiriço, à integração entre nações e às fronteiras enquanto instância simbólica, cultural (Pesavento 2002). Essa consideração nos faz recordar que o próprio conceito de fronteira, embora represente comumente as linhas de culminação de um Estado, já implica a ideia e o incentivo à transcendência em sua gênese (Matthai 1991).

Com isso, a obra representa a fronteira de uma forma alternativa àquela usual na cobertura midiática hegemônica, sem alertar para sua relação com perigos e contravenções (Silveira 2012), na mesma medida em que responde aos estereótipos consolidados sobre fronteira no cinema norte-americano mainstream (Iglesias-Prieto) e às noções de periferia relacionadas a tal espaço (Guerreiro 2015). Isso porque na obra documental a fronteira não é retratada como margem, mas centro de outros fenômenos e relações entre sujeitos, evidenciando as formas com que suas múltiplas experiências de vida e de trocas simbólicas redefinem tal espaço - abordagem reconhecível como o segundo conjunto de aproximações sobre a fronteira enunciado por Iglesias-Prieto (2010) e recuperados na revisão bibliográfica deste trabalho.

Assim, estudar o documentário $\mathrm{Na}$ Fronteira foi pertinente porque o próprio fato de o objeto ter sido produzido em circuito de produção independente já implica em uma força de representação social e política que fomenta outras vias de intenção em sua realização, alinhadas a um viés mais alternativo quanto à forma de fazer audiovisual e que merecem atenção dos estudos em comunicação. 


\section{Filmografia}

Na Fronteira. 2015. Vídeo. Maria Clara Escobar.

\section{Referências bibliográficas}

Canclini, Nestor García. 2003. "Noticias Recientes sobre la Hibridación". Revista Transcultural De Música. http://www.sibetrans.com/trans/trans7/canclini.htm.

Candeas, Alessandro Warley. 2005. "Relações Brasil-Argentina: Uma Análise Dos Avanços e Recuos". Revista Brasileira De Politica Internacional 148 (1): 178-213.

Casetti, Francesco, e Federico Di Chio. 1999. Análisis de la Televisión. Barcelona: Paidós.

França, Andréa. 2002. "Paisagens Fronteiriças no Cinema Contemporâneo". ALCEU 2 (4): 61-75.

Guerreiro, Alexandre Silva. 2015. "Narrativas E Fronteiras Em Duas Jornadas LatinoAmericanas". Significação 42 (44): 254-270.

Gutfreind, Cristiane Freitas. 2006. "O Filme e a Representação do Real". Revista da Associação Nacional dos Programas de Pós-Graduação em Comunicação (E-Compós), n. 6. http://www.compos.org.br/seer/index.php/e-compos/article/view/90/90.

Hall, Stuart. 1997a. "A Centralidade Da Cultura: Notas Sobre As Revoluções Culturais Do Nosso Tempo". Educação \& Realidade 22 (2): 15-46.

Hall, Stuart. 1997b. "The Work of Representation". In Representation: Cultural Representations and Signifying Practices, Londres: Sage/Open University.

Iglesias-Prieto, Norma. 2010. "Trascendiendo Límites: La Frontera México-Estados Unidos En El Cine". Forum for Inter-American Research 3 (2): 1-24. http://interamerica.de/volume-32/iglesias-prieto.

Matthai, Horst. 1991. "El Hombre Y Sus Fronteras". Estudios Sobre Las Culturas Contemporaneas 4 (11): 37-58.

Nichols, Bill. 2005. Introdução ao Documentário. Campinas: Papirus. 
Nogueira, Ricardo José Batista. 2007. "Fronteira: Espaço De Referência Identitária?". Ateliê Geográfico 1 (2): 27-41.

Oliveira, Tito Carlos Machado de. 2015. "Fronteiras de Comunicação: Movimentos, Sentidos e Semblantes.". In Comunicação, Cultura e Fronteiras, 1aa ed., 9-18. Ijuí: Editora Unijuí.

Pesavento, Sandra Jetahy. 2002. "Além das Fronteiras". In Fronteiras Culturais, 35-39. Porto Alegre: Secretaria Municipal de Cultura/Ateliê Editorial.

Ramos, Fernão Pessoa. 2008. Mas Afinal ... O Que É Mesmo Documentário?. São Paulo: Senac.

Silveira, Ada Cristina Machado da. 2012. "A Cobertura Jornalística de Fronteiriços e Favelados - Narrativas Securitárias e Imunização Contra a Diferença". Intercom - RBCC 35 (1): 75-92.

Williams, Raymond. 2003. La Larga Revolución. Buenos Aires: Nueva Vision.

Woodward, Kathryn. 2014. "Identidade e Diferença: Uma Introdução Teórica e Conceitual". In Identidade e Diferença: A Perspectiva Dos Estudos Culturais, 7-72. Petrópolis: Vozes. 